\title{
> Há cidade por vir? Pensamentos para além da metrópole
}

\author{
> Is there city to come? Thoughts for beyond the metropolis
}

\begin{abstract}
por Artur Dória Mota
Doutorando em poéticas e processos de atuação em artes do Programa de Pós-Graduação em Artes do Instituto de Ciências da Arte (ICA) da Universidade Federal do Pará (UFPA), com bolsa CAPES. E-mail: arturdoria@yahoo.com.br. ORCID: 0000-0002-0746-6386.
\end{abstract}

\section{Resumo}

Partindo de dois modelos clássicos que fundamentaram a emergência do conceito do que entendemos hoje enquanto cidade, a polis e a civitas, este texto busca compreender e questionar a cidade contemporânea em sua condição metropolitana, marcada por políticas de imobilidade e sufocamento que demandam uma intensa produção de subjetividades. Trazendo pensadores dos campos da filosofia e da política como Giorgio Agamben, Massimo Cacciari e Vinícius Nicastro Honesko, entre outros, nos propomos a pensar outras chaves de relações para o que denominamos cidade, que sejam capazes de produzir modos de habitá-la para além da metrópole. Uma cidade outra, espaço de composição e transposição de mundos que não se encerre em si mesma; uma cidade ainda por vir.

Palavras-chave: Cidade. Metrópole. Mundo. Política. Habitar.

\begin{abstract}
Starting from two classical models that grounds the emergence of the concept about what we understand today as city, the polis and the civitas, this paper intends to understand and to question the contemporary city in its metropolitan condition, marked by politics of immobility and suffocation that demands an intense production of subjectivities. Bringing thinkers from the fields of philosophy and politics like Giorgio Agamben, Massimo Cacciari, Vinícius Nicastro Honesko, among others, we propose to think other keys of relations for what we call city, which might be able to produce ways of inhabiting it to beyond the metropolis. Another city, space of composition and transposition of worlds that doesn't close in itself; a city yet to come.
\end{abstract}

Keywords: City. Metropolis. World. Politics. Inhabit. 


\section{A condição metropolitana}

O filósofo italiano Giorgio Agamben aponta a metrópole como a constituição de um novo tipo de tecido urbano, novo paradigma de espacialização em que é possível notar, sobretudo, uma máquina de despolitização generalizada, uma ofensiva direta à polis enquanto política (sua concepção clássica), instituindo uma polis polícia $^{1}$, expondo uma confusão obtusa entre zonas públicas e privadas da cidade em que já não há mais um centro irradiador do poder. ${ }^{2}$

Na etimologia da palavra, o termo metrópole, Cidade Mãe em grego, está vinculado à perspectiva daqueles (os colonos) que deixavam a polis, a cidade raiz, para a perigosa empreitada de fundar outras cidades. Há, portanto, uma relação de maternidade entre cidades e territórios de ocupação/habitação, a metrópole situada como um espaço germinativo, de propagação de heterogeneidades. ${ }^{3}$

A noção de metrópole definia-se por seu caráter extensivo, mantendo com a colônia uma referência de ocupação territorial; é como se a polis houvesse encontrado um ponto de fuga, um meio de se deslocar de si mesma, sendo este o próprio pressuposto de sua estabilidade enquanto território habitável. Isso se dava em grande parte porque a polis não aspirava, em sua constituição, a um crescimento demasiado de seu território. Essa ideia trazia à tona o risco do colapso, ocasionado, por sua vez, pelo rompimento com a estrutura de partilha política, de vida comum, que fundamentava e regia a polis. Outro ponto diz

\footnotetext{
${ }^{1}$ Paul Virilio, Velocidade e política, 1996.

${ }^{2}$ Giorgio Agamben, "Metropolis", 2010.

${ }^{3}$ Ibidem.
} 
respeito ao isolamento de cada polis em relação às outras, de modo a evitar interferências ou influências externas nas decisões internas que lhes eram imanentes.

O filósofo italiano Massimo Cacciari aponta que "a polis é precisamente o lugar do ethos, o lugar que serve de sede a determinada gente" ${ }^{m}$. Essa gente comporia um todo unitário, pertencente a uma descendência e etnia comuns em que se partilha da mesma tradição. Isso sugere uma noção de enraizamento, moradia, o lugar em que habito, em que exerço ação; ação esta compreendida sob o aspecto da política, da vida política. A polis grega, deste modo, incute uma ideia de homogeneidade, univocidade, continuidade relacionada a um poder celular no qual a cidade é o próprio poder, atuando como organismo equilibrado e isonômico, cidade-estado. Isso implica dizer que a cidade per si é o espaço político por natureza e os cidadãos ${ }^{5}$ da polis refletem a própria imagem desta.

Cacciari apresenta uma diferenciação entre polis e civitas. A civitas, em oposição à polis, estaria ligada a uma raiz heterogênea presente na formação das cidades romanas: "Roma é fundada pela obra concordante de pessoas que haviam sido, inclusivamente, expulsas das suas cidades $^{\prime 6}$. A cidade passava a ser concebida como uma organização derivada de uma confluência de tipos sem qualquer vínculo de cidadania com outros territórios. $\mathrm{O}$ que sustentava essa reunião conflituosa era a concordância e sua consequente obediência a uma lei que operava em um estrato superior da sociedade.

\footnotetext{
${ }^{4}$ Massimo Cacciari, A cidade, 2010, p. 10.

${ }^{5}$ É importante, entretanto, evidenciar que nem todos eram considerados cidadãos na polis grega; estavam excluídos mulheres, escravos e estrangeiros.

${ }^{6}$ Massimo Cacciari, Op. Cit., 2010, p. 11.
} 
A cidade romana (cidade sede) se estabelece como aquela que dita a lei, que impõe a concórdia ao mundo inteiro, pois o "que junta estes cidadãos tão diferentes não é a sua origem, mas o fim comum"7. Para esta ambiciosa empreitada haveria entranhada uma necessidade de extrapolar os seus derradeiros limites, tornar a cidade móvel (hábil, virtuosa), de fazer dilatar o território, um império que se manifesta diretamente em relação ao tamanho e a sua capacidade de englobar e absorver novos territórios e, com isso, novos povos.

De acordo com o filósofo, trata-se já do embrião, da formulação remota de um processo de globalização que somente se consolidaria ao final do século XX. Isso se justificaria devido a uma herança genética romana apontada por Cacciari em relação às cidades ocidentais, o ocidente tendo evoluído sob as graças - ou a maldição - da necessidade expressiva de expansão e conquista territorial romana que tinha, por finalidade comum, "dar as suas leis ao mundo"

Essa finalidade comum, entretanto, atua como uma conversão para um mundo comum. O universal não está dado de antemão, não pode ser compreendido por uma decodificação comum a todos, um signo referencial que se expandiria para além de sua própria localidade. Ao contrário, sua posição universal não pode ser arrazoada sob um paralelismo de trocas complementares que decairia em uma igualdade de nivelamento (valor de mercadoria, força de trabalho). Um um acrescentando UM, favorecendo uma engorda global. Sua universalidade é imanente, possui valor absoluto, vida plena, sem equivalente quantitativo e revelador de um profundo desacordo.

\footnotetext{
${ }^{7}$ Ibidem, p. 14.

${ }^{8}$ Ibidem.
} 
Tal desacordo primordial denota um pluralismo universal. $\mathrm{O}$ mundo comum não existe, precisa ser composto, como afirma o antropólogo e filósofo francês Bruno Latour. Essa composição, uma arte política em seu entender, não caberia a uma suspensão de divergências em nome de um mundo comum, entranhado como princípio fundamental de todos e que poderia, enfim, ganhar espaço para irromper e se perpetuar:

ele já não está enterrado na natureza, em um universal, dissimulado sob os véus amassados das ideologias e das crenças as quais bastaria deixar de lado para que o acordo se faça. Ele deve ser feito, deve ser criado, deve ser instaurado. E, portanto, pode ser perdido ${ }^{9}$.

Não há como fugir visto que "o pluralismo fere muito profundamente"10, o que coloca, desde já, a estrita necessidade de restaurações constantes. Em suma, aprender a compor com aquilo que não atesta nenhuma garantia: compor com o impossível.

A lei, nesse caso, absoluta, é também o elo frágil que segura este suposto comum acordo. $\mathrm{O}$ fio condutor - ainda que precário, garantia de mobilidade e expansão rumo a uma finalidade comum, visto que ela própria é o atributo comum, dádiva derradeira capaz de unificar o mundo. Nesse modelo, arrisca-se a perder tudo, menos a lei, que garantiria a convivência - ou a conveniência possível da heterogeneidade, essa grande ficção ocidental. Assim, o mundo comum nos alcança, mas nós não podemos alcançá-lo. Ele delibera distante, fardo que devemos suportar em nome de um suposto fardo maior. É possível

\footnotetext{
${ }^{9}$ Bruno Latour, "Não há mundo comum: é preciso compô-lo", 2014, n. p.

${ }^{10}$ Ibidem.
} 
pensar que essa finalidade guarda uma condição de colapso potencial? E o que teria de ser feito para manter o ritmo intermitente desta finalidade global? Mais: que cidade é essa, que se expande de modo exponencial atingindo escalas indefinidas? É ainda possível falar de cidade como um lugar de habitar?

\section{Proliferando cidades: entre o ócio e o negócio}

Cacciari identifica dois modelos de pensamento acerca da cidade, duas concepções decorrentes da polis (grega) e da civitas (romana): de um lado uma cidade que privilegia a troca e a comunicação humana, um lugar para cultivar a moradia, que partilha e acolhe um reconhecimento e um sentimento de comunidade política; de outro, uma cidade instrumentalizada, cidade-máquina, funcional, um espaço que possibilite o desenvolvimento e a movimentação dos negócios, fatores primordiais de crescimento e expansão territorial.

O primeiro modelo é manifestado através do otium (ócio), enquanto o segundo pelos negotia (negócio). O primeiro preza, em princípio, pela coletividade, já o outro, pela individualidade. Esses modos são pensados a partir de uma existência possível na cidade ou em cidade, sendo esta um território que permite, de modo ampliado, específico e coletivo, a realização de determinadas possibilidades de existência. Esses dois modos de vida na cidade derivam diretamente da condição da cidade moderna ocidental e estariam em permanente tensão, visto que, sob demanda - o que queremos, o que estamos a exigir da cidade? -, não poderiam ocorrer ao mesmo tempo. Inevitavelmente um se torna obstáculo imediato do outro. Isso conduz, efetivamente, a um permanente estado de insatisfação, a cidade como espaço de desilusões. De 
acordo com Cacciari, isso faria mover uma alternância quase esquizofrênica entre estes dois desejos de cidade, uma contradição que é a própria gênese da cidade enquanto formação eminentemente humana.

Não obstante essas colocações, Cacciari reconhece a predominância, para não dizer a supremacia, dos negotia sobre o otium - ainda que sob outras égides de topologia políticas bem distintas das cidades do mundo antigo - que coincide com o surgimento da burguesia e a consequente consolidação do capitalismo nos séculos vindouros; o que, vale ressaltar, fora um dos responsáveis diretos pelo processo de colonização e imperialismo nas Américas: "entre os séculos XV e XX houve a destruição, em nome da cidade instrumento, de tudo aquilo que na cidade anterior impedia este movimento, obstaculizava as dinâmicas dos negotia"11.

Mas o ócio, longe de ter sido eliminado, é então apropriado a partir de uma reversão ideológica ao próprio negócio, que passou ao longo dos anos por uma profunda mutação - emergindo sob outros formatos e interesses - tendo como pano de fundo uma realidade econômica produtiva. O ócio fora submetido a um processo de regulamentação. Passa a ser governado, tendo sido destituído e colonizado, por fim, de seu princípio fundamental de existência, passando a ser vinculado a uma vontade que delibera a sua pertinência. A contradição fora apartada e diluída na própria constituição da vida nas cidades.

O neg-ócio como um negativo imperativo do ócio, marca uma transição que nada mais é do que um apaziguamento violento, devendo agora ser sancionado

\footnotetext{
${ }^{11}$ Massimo Cacciari, Op. Cit., 2010, p. 26.
} 
por uma classe sacerdotal, que deteria o domínio de um ócio dito sagrado (o sacerdócio), ganhando valores de distinção social. Segundo a observação dos pesquisadores Alexandre Nodari e Flávia Cera a partir dos escritos de Oswald de Andrade: "a classe sacerdotal [...] seria aquela que, sacralizando o ócio (dogma), cria as regras (ritos) e os discursos (mitos) que controlam o acesso futuro ao ócio enquanto prêmio por atividades presentes"12.

O ócio torna-se, no paradigma do mundo moderno, um dispositivo de motivação para abraçar a direção a uma causa comum: seria a promessa que negocia o futuro mediante uma dívida existencial? "O negócio, assim, é a conversão das artes, dos fazeres, em trabalho, por meio do estorvo ideológico sacerdotal que separa a atividade (produtiva) do ócio (improdutivo)"13, afirmam Nodari e Cera. Um agregado institucional, ancorado a um direito que repousa amordaçado sob a sombra do negócio, aprimorado sob o ideal de trabalho, não pode mais circular livremente, circunscrito a determinadas condições. O ócio oswaldiano, por sua vez, é "um fazer esvaziado de determinações externas" ${ }^{14}$.

O sacerdócio acaba por se conectar a outro modus operandi dessa expansão territorial imputado pelo ocidente europeu: "de fato, a urbanização, em diferentes formas, foi o modo privilegiado de estabelecer a colonização, de civilizar o 'selvagem'"15. Não à toa a Igreja, como lembrado por Cacciari, se apropriou de modo muito eficaz, aprimorando conforme seus ideais, as ideias provenientes do direito constitucional romano.

\footnotetext{
${ }^{12}$ Flávia Cera e Alexandre Nodari, “Vagamundear”, 2016, p. 21

${ }^{13}$ Ibidem.

${ }^{14}$ Ibidem, p. 20.

${ }^{15}$ Alexandre Nodari, “"Selva de pedra"? A floresta e a cidade”, 2015, n. p.
} 
Esse modelo de formação urbana traz à tona a questão do que deve e pode estar dentro da cidade, aquilo ou aqueles que a cidade acolhe ou exclui. Se antes a expansão territorial estava fundamentada em uma heterogeneidade que, de certo modo, contemplava um gozo de tradições que desfrutavam de certa liberdade, agora essa mesma heterogeneidade é alvo de um rigoroso controle, confinada a um espectro de vigilância cotidiana.

A conquista urbana - sinal de elevação espiritual do projeto ocidental moderno colonial - revela nada mais do que uma conquista em relação àquilo que se constitui enquanto ameaça aos muros da cidade. ${ }^{16} \mathrm{O}$ fora da cidade (a floresta) deve ser restrito ao homem, lugar perigoso, é o lugar em que o indivíduo se desumaniza. É onde sobrevive o selvagem em ambiente precário, levando uma vida arcaica e ignorante aos modos superiores que formam a civilização. A cidade aparece neste panorama como uma imagem que preconiza a segurança e um habitat possível; sob seus limites, seus muros, o ser humano pode se reconhecer e se afirmar enquanto homem.

A terra não urbanizada, estriada, recortada, regulada e distribuída, deveria ser tomada, possuída por esse caráter derradeiro. A necessidade de transformar a terra em urbe através de uma radiosa materialização de um mundo de possibilidades - a autoafirmação da mobilidade, independência móvel? - em que predominam símbolos de posse.

A floresta apresenta-se, portanto, como exterioridade à cidade (Estado), habitat do silvaticus, do selvagem (o Fora da floresta é também um fora da condição civilizada), o qual só pode ser eliminado completa e eficazmente

${ }^{16}$ Conquista, nesse sentido, como sinônimo de invasão, pilhagem, destruição e morte. 
com a modificação ou aniquilamento do espaço geográfico-político (e mesmo ontológico) que ocupa - ou seja, por meio de uma retopologização ${ }^{17}$.

A nossa formação urbana, sob este limiar, deve ser compreendida como uma imposição colonial. ${ }^{18}$ Nossa educação urbana é a reprodução imposta simulacro, na verdade. Como tal, ineficiente e sempre a manquejar - de um pensamento colonial cristão ocidental. Fomos formados e modelados sob o riste genocida de uma ordenação espacial geográfica que não reconhecemos e que sempre nos atropelou. $\mathrm{O}$ próprio conceito e a imagética da cidade, do que seria uma cidade, reverbera em uma cultura compreendida sob aspectos ontológicos e epistemológicos externos que nunca nos pertenceu, presença alienígena que, ao contrário, despossuiu, despovoou.

Ao regular o ócio - consideremos sua espessura conceitual e prática -, a quem e de qual modo estamos regulando os espaços? Giorgio Agamben irá referir-se à análise perpetrada pelo filósofo e historiador francês Michel Foucault acerca de dois paradigmas médicos de ordenação e territorialização espacial urbana. Estes marcam a transição do antigo regime em detrimento do biopoder moderno, o que, segundo Agamben, aponta para duas características fundamentais deste espaço urbano emergente, marcado pela governabilidade: a lepra e a peste. ${ }^{19} \mathrm{~A}$ primeira trata da exclusão, a cidade que fecha os portões para o leproso. O doente deve ser retirado da cidade a fim de mantê-la em estado de pureza; uma limpeza étnica em seu sentido mais estrito. A segunda, por se tratar

\footnotetext{
${ }^{17}$ Alexandre Nodari, Op. Cit., 2015, n. p.

${ }^{18}$ Nos referimos ao contexto histórico das cidades brasileiras e, mais amplamente, das cidades latino-americanas.

${ }^{19}$ Giorgio Agamben, Op. Cit., 2010.
} 
de uma epidemia generalizada, evoca a impossibilidade de exclusão, dando lugar a uma vigilância de confinamento. É o paradigma das técnicas disciplinares, de produção de tecnologias que visam individualizar e enclausurar o pestilento: "o que acontece na formação dos espaços urbanos contemporâneos, desse modo, é que os dois paradigmas começam a fundir-se de maneira a lançar o esquema de vigilância da peste sobre aquele da lepra e vice versa" ${ }^{20}$.

A isto podemos acrescentar um desvio que deve funcionar como ponto de fuga a estes paradigmas. A negativa do ócio enquanto prerrogativa existencial, que nada mais é do que a chegada do poder disciplinar sobre o qual Foucault se debruça, parece funcionar de maneira mais ou menos efetiva dentro de domínios específicos. Como se houvesse um insuportável natural (a ameaça, o inimigo constante) a qualquer tipo de aproximação ou vizinhança. A mistura não poderia ser tolerada; haveria um temor implícito, uma contaminação possível? Há, portanto, que se destacar aqueles que não aderem a essa separação constituinte. São os que escapam aos parâmetros sociais definidos de antemão e parecem tecer o negativo do negativo. Lembremos a este respeito dos nômades: "os únicos que ocupam a terra, que "seguem" a terra, que estão em uma relação de imanência com ela, [...]. Eles estão sempre se deslocando sobre um espaço sem território"21.

\footnotetext{
${ }^{20}$ Vinícius Nicastro Honesko. "Reflexões sobre os espaços urbanos contemporâneos: quais as nossas cidades?", 2016, p. 10.

${ }^{21}$ David Lapoujade, Deleuze, os movimentos aberrantes, 2015, p. 41.
} 


\title{
3. Dispositivos de subjetivação e controle
}

Como modelo incipiente, a metrópole inaugura um padrão específico de cidade contemporânea, constitui-se como uma forma entre formas a ser decalcada infinitamente. Em sua portentosa organicidade acaba por se distanciar de qualquer caráter de singularidade e distinção, sendo o processo de urbanização nada mais do que a substancial e corrente adequação das formas sempre em constante dissolução e reformulação - a uma matriz de funcionamento global e unitária.

\begin{abstract}
A metrópole não é mais do que essa amalgama urbanizada, esta colisão final entre a cidade e o campo, e simultaneamente um fluxo de seres e de coisas. [...]. Uma corrente que desejaria tudo agrupar na sua mobilidade sem esperança, que mobiliza cada um. Onde estamos sitiados por informações, como por outras tantas forças hostis ${ }^{22}$.
\end{abstract}

Um espaço primordial que permite tanto quanto veicula aquilo que o filósofo francês Gilles Deleuze irá nomear de sociedades de controle, avançando nos estudos realizados por Foucault acerca das sociedades disciplinares. "Os controles são uma modulação, como uma moldagem auto deformante que mudasse continuamente" ${ }^{23}$. Segundo Deleuze, vivemos precisamente um ponto de transição entre essas duas sociedades. O momento é de crise, um transtorno institucionalizado dos meios técnicos de confinamento, que já não funcionam conforme sua expressão maquínica capaz de projetar e normatizar os comportamentos sociais. Mas essa transição revela, sobretudo, uma mistura para

\footnotetext{
${ }^{22}$ Comitê Invisível, A insurreição que vem, 2013, p. 58-59.

${ }^{23}$ Gilles Deleuze, Conversações: 1971-1995, 2013, p. 226.
} 
além da combinação dos paradigmas expressos por Foucault. Um processo que nos transborda, uma metamorfose do poder e, por conseguinte, dos modos de produção de subjetividade, ou ainda, dos modos como somos governados: "os dispositivos de controle começam a funcionar como mecanismos fundamentais para a individualização e subjetivação dos habitantes do espaço urbano, ou seja, para a sua gestão e controle"24.

Desse processo, como consequência direta, instala-se a crise como prática, técnica de governo; o governo funcionando, basicamente, como um gabinete de crise. A crise enquanto ferramenta retórica é o dispositivo de controle do governo por excelência, o motivo político que gerencia e produz a vida na metrópole, "fala-se de "crise" a propósito daquilo que se pretende restaurar" 25 . Ou ainda, o fato essencial que coroa a própria capacidade de mutação do capitalismo, que parece nunca perder de vista seu foco: "a "crise" significa: o governo cresce" ${ }^{26}$. Para um governo crescer - para exercer poder enquanto governo e inseminar a propagação do capitalismo - é necessário estimular o crescimento ritmado e irrestrito das cidades. Um crescimento não exclusivamente vinculado a uma conquista territorial ou a um imperativo de leis, mas a um crescente domínio sobre a vida e os modos de existência que povoam as cidades.

Em cada metrópole as urgências se reforçam como se estivéssemos sobrepostos a um campo continuum ilimitado, não mais um começar do zero, mas um nunca finalizar, um encadeamento sem fim que é um fim em si mesmo. Uma aceleração incessante de movimentos e fluxos permanentes; a mobilidade

\footnotetext{
${ }^{24}$ Vinícius Nicastro Honesko, Op. Cit., 2016, p. 11.

${ }^{25}$ Comitê Invisível, Aos nossos amigos: crise e insurreição, 2016, p. 25.

${ }^{26}$ Ibidem, p. 27.
} 
ininterrupta é o programa da vez. Desse modo, o espaço urbano parece padecer de um violento acesso de reformulações, em que o mais importante, sobremodo, é a produção contínua de infraestruturas que nos cabem tão somente ao usufruto, como se a cada novo ambiente estivéssemos diante de uma nova cidade. ${ }^{27}$ Ao fazer e refazer a cidade circular para que não possamos percebê-la, somos forçados a nos espraiar pela cidade transformada em espaço rotativo a fim de que não possamos localizá-la. A cidade não tem lugar e o que se visualiza nada mais é do que um vazio enorme. Um vazio que evoca a demanda de um pretenso preenchimento, um vazio deserto de duração reiterada. Como produto da dinamização aceleracionista de todos os aspectos da vida, a cidade fora reduzida, mediante virulenta espetacularização, a um centro comercial de circulação de produtos.

É desse modo que Agamben lança sua preocupação. A metrópole aparece como o lugar em que se evidenciam esses processos, sendo na verdade o campo mesmo onde eles se realizam. A metrópole, a imponente metrópole, é “o dispositivo, ou o conjunto de dispositivos, que toma o lugar da cidade quando o poder assume a forma de um governo de homens e coisas"28. Um imenso campo de produção de subjetividades, do qual, segundo Agamben, ainda temos pouco conhecimento. Esse saber, por sua vez, estaria diretamente implicado a uma modulação de nossa capacidade de ação, o que caberia penetrar profundamente

\footnotetext{
${ }^{27}$ Essa ideia do novo pode ser pensada pelo que o filósofo sul coreano Byung-Chul Han (2015) chamou de excesso de positividade ou positivação do mundo, que caracterizaria uma sociedade do desempenho em substituição ao paradigma da sociedade disciplinar.

${ }^{28}$ Giorgio Agamben, Op. Cit., 2010, p. 2.
} 
nestes novos processos e implodi-los, tornando-os ingovernáveis, levando-os aos limites de si mesmos.

Sobre isso, o filósofo francês Jean-Luc Nancy aponta para um estado de ignorância e impotência frente a uma profunda mudança, uma ruptura histórica, senão uma ruptura com a própria história, o que nos colocaria em um momento pós-pós, ou seja, um período pré. ${ }^{29}$ Diante disso, a começar a ruir o tempo-espaço conhecido, nossa capacidade de fazer e pensar entra em crise, e somos levados a evitar a perplexidade deste algo que já nos ultrapassa ferozmente, o qual não poderemos alcançar. Segundo Nancy, há que se tomar outro rumo em nossas questões mais essenciais, não mais submetidas a um que fazer, mas a um qual fazer?, do que queremos falar?; uma virada que remonta diretamente à necessidade extrema que denota nossa época de compor o mundo do qual exprime Bruno Latour.

Nesse sentido, a metrópole seria o ponto onde a cidade, como objetivo final da humanidade (completando a ambição romana) enquanto civilização sedentária - visto que o mundo colonial é sempre um mundo de imobilidade -, entra em colapso ${ }^{30}$ Esse colapso coroa um esgotamento, reiteradamente acobertado por meio de sobreposições de crises que subvencionam a economia do desastre, e como tal, chegamos a um ponto de não retorno. Será possível escapar da metrópole, ou, de outro modo, há cidade por vir?

\footnotetext{
${ }^{29}$ Jean-Luc Nancy, "O comunismo é o sentido do ser-em-comum por pensar", 2014.

${ }^{30}$ Frantz Fanon, Os condenados da terra, 1968.
} 


\section{Destituir a metrópole: por um fazer corpo-cidade}

É importante, contudo, perguntar: o que exatamente se esgotou? Nossa capacidade de agir? E mais: não há saída? Estamos condenados a esta lógica de sufocamento perpétuo? Não temos para onde correr, apesar de drenados - espiral do cansaço, sociedade do cansaço, de atividade intermitente ${ }^{31}$ - por um paradoxo imperativo em que somos forçados a correr por todos os lados sem chegar a lugar algum? Se a cidade nos toma em um caráter de urgência por todos os poros, se somos atraídos por toda sorte de chamados e sirenes anunciando a nova crise que nos reduz a uma posição inócua e descrente, devemos ter a clareza de um esgotamento dos recursos subjetivos; $;^{32}$ por consequência, da nossa própria relação com o mundo, decadente, em frangalhos, catastrófica, em que fomos destituídos de mundo. Não há mais um mundo ao qual nos conectar, não temos mais cidade.

Talvez precisemos, antes de tudo - não para esquivar a essas questões, mas para relacionar um componente ético capaz de nos dar impulsão, que acenda as nossas pulsões -, nos expormos a uma renúncia como imperativo básico, um mínimo comum a todos:

Para tornar irreversível a destituição é necessário, portanto, começar renunciando à nossa própria legitimidade. Temos de abandonar a ideia de que se faz revolução em nome de algo, que haverá uma entidade, essencialmente justa e inocente, que as forças revolucionárias seriam incumbidas de representar. Não se manda o poder por terra para elevar a si mesmo para os céus ${ }^{33}$.

\footnotetext{
${ }^{31}$ Byung-Chul Han, Sociedade do cansaço, 2015.

${ }^{32}$ Comitê Invisível, Op. Cit., 2016, p. 37.

${ }^{33}$ Ibidem, p. 91.
} 
A cidade-metrópole deve ser destituída de seus dispositivos de controle, de sua condição enquanto projeto biopolítico. Trata-se de destituir, portanto, a própria ideia de que os homens devem ser governados: nos tornar ingovernáveis. O paradigma do governo, da necessidade do governo, de que é preciso governar, parte de um pressuposto antropológico que encarna uma natureza humana (selvagem, animalesca) que deve ser contida, controlada. No cerne das cidades contemporâneas há esse viés, essa tentativa de aplacar um instinto primitivo - os leprosos e os pestilentos estão sujeitos a essa triagem e também todos aqueles que não servem à cidade ou à determinada ordenação social mantida pela cidade -, essa alma inconstante, que poderia ainda assombrar o defunto projeto civilizatório, como uma doença incubada, sempre à espreita e demandando acompanhamento irremediável, como medida de segurança preventiva. Seria a guerra de todos contra todos proclamada por Hobbes?

Somos todos suspeitos. Devemos o ser, afinal; e como tal, não nos esqueçamos dos que não têm classe, dos que se negam a seguir qualquer plano ou projeto direcional que os conduza a um pressuposto fim. São estes, os que se recusam a ser tidos como homens se para tal têm de seguir as linhas estriadas que gerenciam suas vidas, os traidores da espécie. Suas presenças, múltiplas e desprovidas de lugar, se constituem por si só como destituição ontológica que atua como "uma declaração de guerra contra o Homem" ${ }^{34}$. Isto é adensado por uma expressa noção de povoamento, dado que a metrópole, ao expropriar a nossa capacidade de habitar a cidade, produz um despovoamento progressivo. Declarar

\footnotetext{
${ }^{34}$ Comitê Invisível, Op. Cit., 2016, p. 39.
} 
guerra ao Homem implica, sobretudo, povoar; tornarmo-nos povo, povo que falta, "um povo ambulante de revezadores, em lugar de uma cidade modelo" ${ }^{35}$.

Destituir é trazer a batalha para outro plano. Este, o plano em que nós já não somos ninguém, em que rompemos as malhas do discurso, onde o discurso fora fraturado de seu caráter epistemológico. Batalha essa que não deve ser ofuscada pela espiral violenta da crise: "não há uma "crise" que precisamos sair, há uma guerra que precisamos ganhar" ${ }^{36}$. Destituir, então, todos os nomes que nos elevam a uma caricatura identitária, sabendo de antemão que "a liberdade passa pela capacidade de destituir o Outro da força da enunciação dos regimes de visibilidade possíveis" ${ }^{\prime 3}$. É essa a cilada que se deve evitar. Não falamos em suspender os papéis sociais momentaneamente, nada de elevações ou aspirações extraterrenas. Trata-se de fazer descer à Terra, o poder colocado na linha de frente, no corpo a corpo da vida, humilhado e desguarnecido de suas técnicas fundamentais de governo, obrigado a se defender sem a confortável regalia de modular o curso de nossas próprias ações.

Por fim, é preciso ter em mente que para agir é necessário corpo: “não há, nem nunca haverá política possível sem corpo" ${ }^{38}$. Mas como fazer emergir outro corpo, resistente aos assaltos e as urgências impulsionadas pelos fluxos abusivos e excludentes da metrópole?

É nesse sentido que, para instaurar a pergunta-dúvida qual fazer? (qual corpo queremos?), talvez seja preciso nos dedicarmos também a um determinado

\footnotetext{
${ }^{35}$ Gilles Deleuze e Felix Guattari, Mil platôs - capitalismo e esquizofrenia, v. 5,1997, p. 47.

${ }^{36}$ Comitê Invisível, Op. Cit., 2016, p. 19.

${ }^{37}$ Vladimir Safatle, Quando as ruas queimam: manifesto pela emergência, 2016, p. 6-7.

${ }^{38}$ Ibidem, p. 13.
} 
rigor, que passaria inevitavelmente pela constituição de nossos próprios corpos como propulsores de um outro agenciamento político. Um agenciamento capaz de nos colocar frente a outro pensamento de cidade (pensamento corpo-cidade) para além da metrópole, a cidade como um mundo possível e desejável, em que estejamos em relação existencial com os espaços e com os outros, humanos e não humanos. O que poderia, de imediato, se configurar como um levante sobre e com a Terra.

O que nos falta é rigor. Sim, rigor: a mais estranha de todas as paixões, esta que queima e constrói. Nenhuma verdadeira construção se ergueu sem essa impressionante crueldade de artista que se volta contra si mesmo até produzir dos seus próprios desejos a plasticidade do que faz nascer de si toda forma. Só a verdadeira disciplina, esta que não é repressão e nem submissão da minha vontade a vontade de um outro, mas que é trabalho sobre si, que é produção de uma revolução na sensibilidade, salva. Uma disciplina de $\operatorname{artista}^{39}$.

\section{A indigestão do corpo}

Toda metrópole é uma necrópole

Roberto Piva

Ao situar o corpo enquanto problemática, sendo este o indício mesmo de nosso empobrecimento subjetivo em conexão com o mundo, interrogamos diretamente nossa capacidade de agir. Por que caminhos podemos impulsionar

${ }^{39}$ Ibidem, p. 29. 
canais de criação sensível que despertem presenças, capazes de transbordar possibilidades através de outras emergências corpóreas?

O corpo que antes tinha o status de um animal utilitário hoje tem o status de um animal de estimação: não é um meio de transporte real, como poderia ser um cavalo; em vez disso, o corpo é exercitado como se levássemos o cão para passear. Assim o corpo, uma entidade recreativa e não utilitária, não trabalha, mas é trabalhado ${ }^{40}$.

O sociólogo e historiador norte-americano Richard Sennet, por sua vez, atenta para uma conformação corpórea em prol de determinada configuração dos espaços urbanos: "navegar pela geografia da sociedade moderna requer muito pouco esforço físico e, por isso, quase nenhuma vinculação com o que está ao redor" ${ }^{\prime \prime 1}$. Trata-se de um esvaziamento progressivo das atividades do corpo enquanto eixo relacional de circulação de forças e saberes - na constituição gradativa de nossos espaços-cidade. O corpo é violentamente ultrapassado, tratado como indesejável e destituído de suas pulsões afirmativas, tanto participativa quanto perceptiva.

A cidade-metrópole, assim, não conta. Ela é contabilizada através de espaços que traçam um perfil familiar (atuam como instrumentos de manutenção política) e que estão ali simplesmente para serem desfrutados, espaços buffets em que qualquer um que possa pagar pode servir-se à vontade. Há um discurso que situa e define a cidade de acordo com a sua capacidade de fazer. Seus poderes de produção e consumo precisam ser exibidos, exacerbados

\footnotetext{
${ }^{40}$ Rebecca Solnit, A História do caminhar, 2016, p. 435

${ }^{41}$ Richard Sennet, Carne e pedra: o corpo e a cidade na civilização ocidental, 2014, p. 17
} 
cotidianamente. Mais coisas, menos corpo. Para isso, é preciso haver uma compressão para acolher uma identidade a priori. A cidade não dá conta da cidade: cidade indigesta, cidade que não gesta.

Estes esvaziamentos, ou atrofias, são indícios de subjetividades amainadas, sufocadas de sua força no mundo - ou melhor, de sua força de mundo. Subjetividades destituídas, desprovidas de sua potência, caladas em detrimento de um modelo genérico de subjetividade dominante. E assim, ser engolido pela cidade, de outro modo, é ser rapidamente regurgitado. A cidade engole, mas não devora, não é capaz de digerir. Consome, mas não é consumida. Mostra as bocas, os dentes, mas não os utiliza, não mastiga (talvez porque os aparelhos não deixem?) em um falso consumo, ainda que consumo. A cidade opera por desgastes, e o que sobra desse consumo é sempre o mesmo, agora embebido da experiência de quase ter sido transformado em outra coisa. Resta o trauma, o fantasma da quase transformação. A quase devoração se torna ameaça porque o consumo nunca é realizado, e nem poderia, se assim fizesse a própria cidade deixar de ser cidade, ou somente cidade. Ela não quer a via de mão dupla, não quer o corpo como espaço de criação.

Este trabalho sobre si, esta disciplina de artista a que se refere Safatle, é precisamente o movimento de abrir passagens para pensar em modos de perfurar e subverter esta insólita terra urbana, este chão concretado, estéril e árido. Que esse movimento, nesse entrecruzo, possa se afirmar como um ponto de virada subjetiva, em que o fortalecimento do corpo - como fortaleza ativa do corpo - seja presumido como sucessão de atos direcionados à perspectiva de um mundo cada vez mais hostil. 
Trata-se, desde já, de propor o agenciamento, a reconversão daquilo que a cidade pode enquanto corpo, partindo sempre da produção de outro corpo, não obstante, exposto e carregando em si outras materialidades da cidade. Materialidades, essas, capazes de suportá-la em suas densidades destrutivas e transformá-las em combustíveis de criação performativa em direção à liberação das demandas que impedem a vida. Aprender a gerar junto e interpenetrando-se frente a movimentos de criação compartilhada que não se julguem independentes entre si. Um cuidar, portanto, que não tem por objetivo blindar-se ou esquivar-se da cidade e das cidades embutidas nela. Pelo contrário. É um cuidado criativo, sempre coletivo, que se dá entre agências humanas e nãohumanas, entregue a atos sucessivos de criação que funcionem como rotas de fuga em relação à metrópole. Uma vivência singular que se refere, em último ato, aos modos de habitar e povoar a cidade, percebida como este espaço imediato, 0 nosso entorno que, na maioria das vezes, não convém. Um cuidar talhado a partir das margens, sobras e vísceras de tudo aquilo que ninguém quer, mas que temos em abundante disposição. Para criar corpo, diga-se, é preciso imaginação.

Ele se movimenta. É capaz de transitar entre universos paralelos. É também o resiliente, aquele sob o signo de Proteu que se metamorfoseia na medida da necessidade de criar existências e de recriar a sua existência; ser 
serpente, que constantemente muda de pele e está sempre a inaugurar um caminhar fértil com o mundo.

\section{Referências}

AGAMBEN, Giorgio. Metropolis. Revista Sopro - Editora Cultura e Barbárie, Florianópolis, n. 26, abr. 2010. Disponível em:

http://culturaebarbarie.org/sopro/verbetes/metropolis.html. Acesso em: 17 mai. 2020.

CACCIARI, Massimo. A cidade. Barcelona: Editorial Gustavo Gili, 2010.

CERA, Flávia; NODARI, Alexandre. Vagamundear. Revista Abrigo Portátil, Curitiba, n. 2, p. 20-25, mai. 2016.

COMITÊ INVISÍVEL. A insurreição que vem. Brasil: Edições Baratas, 2013.

COMITÊ INVISÍVEL. Aos nossos amigos: crise e insurreição. São Paulo: N-1 edições, 2016.

DELEUZE, Gilles. Conversações: 1971-1995. São Paulo: Editora 34, 2013.

DELEUZE, Gilles; GUATTARI, Félix. Mil platôs - capitalismo e esquizofrenia, v. 5. São Paulo: Editora 34, 1997.

FANON, Frantz. Os condenados da terra. Rio de Janeiro: Civilização Brasileira,1968.

HAN, Byung-Chul. Sociedade do cansaço. Petrópolis: Vozes, 2015. 
HONESKO, Vinícius Nicastro. Reflexões sobre os espaços urbanos contemporâneos: quais as nossas cidades?. Cadernos IHU Ideias - Universidade do Rio dos Sinos, São Leopoldo, v. 14, n. 253, p. 2-30, 2016.

LAPOUJADE, David. Deleuze, os movimentos aberrantes. São Paulo: N-1 edições, 2015.

LATOUR, Bruno. Não há mundo comum: é preciso compô-lo. Flanagens. 2014. Disponível em: https://bitlybr.com/PzPjF. Acesso em: 04 fev. 2020.

NANCY, Jean-Luc. O comunismo é o sentido do ser-em-comum por pensar. Flanagens. 2014. Disponível em: https://bitlybr.com/NW8Vb. Acesso em: 04 fev. 2020.

NODARI, Alexandre. "Selva de pedra"? A floresta e a cidade. Partes sem um todo. 2015. Disponível em: https://bitlybr.com/q7upB. Acesso em: 04 fev. 2020.

SAFATLE, Vladimir. Quando as ruas queimam: manifesto pela emergência. São Paulo: N-1 edições, 2016.

SENNET, Richard. Carne e pedra: o corpo e a cidade na civilização ocidental. Rio de Janeiro: BestBolso, 2014.

SOLNIT, Rebecca. A História do caminhar. São Paulo: Martins Fontes, 2016.

VIRILIO, Paul. Velocidade e política. São Paulo: Estação Liberdade, 1996.

\section{Referência para citação deste artigo}

MOTA, Arthur Dória. Há cidade por vir? Pensamentos para além da metrópole. Revista PHILIA | Filosofia, Literatura \& Arte, Porto Alegre, volume 2, número 1, p. $91-114$, junho de 2020. 